University of Nebraska - Lincoln

DigitalCommons@University of Nebraska - Lincoln

Control of Sawtoothed Grain Beetles (Coleoptera: Silvanidae) in Stored Oats by Using an Entomopathogenic Fungus in Conjunction with Seed Resistance

James E. Throne

USDA-ARS, Manhattan, KS, james.throne@ars.usda.gov

Jeffrey C. Lord

USDA-ARS

Follow this and additional works at: https://digitalcommons.unl.edu/usdaarsfacpub

Throne, James E. and Lord, Jeffrey C., "Control of Sawtoothed Grain Beetles (Coleoptera: Silvanidae) in Stored Oats by Using an Entomopathogenic Fungus in Conjunction with Seed Resistance" (2004).

Publications from USDA-ARS / UNL Faculty. 2021.

https://digitalcommons.unl.edu/usdaarsfacpub/2021

This Article is brought to you for free and open access by the U.S. Department of Agriculture: Agricultural Research Service, Lincoln, Nebraska at DigitalCommons@University of Nebraska - Lincoln. It has been accepted for inclusion in Publications from USDA-ARS / UNL Faculty by an authorized administrator of DigitalCommons@University of Nebraska - Lincoln. 


\title{
Control of Sawtoothed Grain Beetles (Coleoptera: Silvanidae) in Stored Oats by Using an Entomopathogenic Fungus in Conjunction with Seed Resistance
}

\author{
JAMES E. THRONE AND JEFFREY C. LORD \\ USDA-ARS, Grain Marketing and Production Research Center, 1515 College Avenue, Manhattan KS 66502
}

J. Econ. Entomol. 97(5): 1765-1771 (2004)

\begin{abstract}
We tested the hypothesis that the entomopathogenic fungus Beaveria bassiana would be more efficacious on oat cultivars that prolonged the immature developmental period of sawtoothed grain beetle, Oryzaephilus surinamensis (L.), a storage pest. However, percentage of reduction in progeny production was similar on whole 'Don' and 'Paul' oats treated with fungus, even though immature developmental time was longer on whole 'Don' than on 'Paul' oats. In our initial test at $10 \mathrm{mg}$ of conidia per kilogram of oats, the number of beetle progeny produced was reduced by $38-67 \%$ in whole oats, and there was no effect of the fungus on insects developing on cracked oats. Therefore, we conducted two dose-response studies that showed that adding $150 \mathrm{mg}$ of conidia per kilogram to cracked or whole 'Paul' oats resulted in a 70 and $98 \%$ reduction, respectively, in number of progeny produced. No further reduction was obtained by adding $200 \mathrm{mg}$ of conidia per kilogram of cracked or whole 'Paul' oats. Presence of the fungus did not affect developmental time in any of our tests. A previous study showed that cleaned oats should limit insect population growth to allow long-term storage of oats without insect damage. However, the current study shows that if the oats are not cleaned, and not cleaning oats is the normal storage practice, then B. bassiana could be used to help control sawtoothed grain beetles.
\end{abstract}

KEY WORDS Beauveria bassiana, host plant resistance, pathogen, stored products, tritrophic interaction

Approximately 125 million BUSHels of oats, Avena sativa L., are harvested in the United States each year (USDA, NASS 2003), and stored oats are susceptible to infestation by insects (Ingemansen et al. 1986). Residual insecticides are used to control insect pests of stored oats, but alternative control strategies are desirable because of the loss of insecticides due to resistance and reregistration and because of consumer desire for pesticide-free grain (Arthur 1996). One alternative control strategy is the use of resistant oat cultivars. Some oat cultivars are relatively resistant to storage insect pests, and whole oats are more resistant than broken oats (Throne et al. 2003). Simulations indicate that insect populations would die out over time on cleaned oats, whereas broken oats support rapid population development (Throne et al. 2003). However, cleaning oats before storage is not a common practice, so bins of oats contain broken kernels. Thus, selecting relatively resistant cultivars for planting and storage would not eliminate insect problems in stored oats.

Mention of trade names or commercial products in this publication is solely for the purpose of providing specific information and does not imply recommendation or endorsement by the U.S. Department of Agriculture.
Two control strategies that each provide moderate levels of control when used together may provide control of a pest at a level that keeps the population below a treatment threshold (Throne 1989). Host plant resistance is generally considered to be compatible with other management strategies, and these combined control strategies can be key components of an integrated pest management program (Panda and Khush 1995, Throne et al. 2000). Thus, we hypothesized that combining use of a natural enemy with the use of resistant oat cultivars might provide a higher level of control of insect pests of stored oats than either method alone and that the two control strategies when used together might result in economically acceptable levels of control. However, there are mixed reports about the effects of host plant resistance mechanisms on natural enemies. For example, Schmale et al. (2003) showed that combined use of the parasitoid Dinarmus basalis (Rondani) with moderately resistant bean varieties that prolong duration of larval development of the stored bean pest the bean weevil, Acanthoscelides obtectus (Say), resulted in decreased damage to the beans, although the most resistant variety negatively impacted parasitoid population development, resulting in damage levels similar to that of the susceptible control. Toews et al. 
(2001) reported that wheat resistance did not impact efficacy of the parasitoid Theocolax elegans (Westwood) for control of the lesser grain borer, Rhyzopertha dominica (F.), developing in stored wheat. Fuentes-Contreras et al. (1998) reported that wheat resistance could negatively impact the efficacy of the entomopathogenic fungus Erynia neoaphidis for control of the grain aphid, Sitobion avenae (F.), but that the impact depended on the timing of parasitoid oviposition and fungal infection. Pfannenstiel and Yeargan (1998) reported that feeding on prey that had fed on resistant soybean plants negatively impacted developmental time and fecundity of the predator Nabis roseipennis Reuter. Thus, it is not possible to predict the possible interaction of host plant resistance with natural enemies for control of a pest.

In this study, we investigated the combined use of resistant oat cultivars and the entomopathogenic fungus Beauveria bassiana for control of the sawtoothed grain beetle, Oryzaephilus surinamensis (L.) (Coleoptera: Silvanidae). The sawtoothed grain beetle was chosen for the study because it is a prolific pest of oats. B. bassiana has previously been shown to provide moderate to high levels of control of O. surinamensis in stored grain. Lord (2001) reported that use of B. bassiana resulted in $72 \%$ mortality of adult $O$. surinamensis when the fungus was applied at $300 \mathrm{mg}$ of conidia per kilogram of wheat ( $300 \mathrm{ppm})$. Searle and Doberski (1984) reported a 91\% reduction in O. surinamensis larvae and pupae in cultures treated with $10^{9}$ conidia per $50 \mathrm{~g}$ of culture medium $(\approx 317 \mathrm{ppm}$, based on weight of conidia as determined in the current study). B. bassiana also has been shown to provide moderate to high levels of control of other stored-product insect pests, including the maize weevil, Sitophilus zeamais Motschulsky (Adane et al. 1996, Hidalgo et al. 1998); the rice weevil, Sitophilus oryzae (L.) (Rice and Cogburn 1999, Dal Bello et al. 2001, Padín et al. 2002); the larger grain borer, Prostephanus truncatus (Horn) (Bourassa et al. 2001, Meikle et al. 2001); the lesser grain borer, Rhyzopertha dominica (F.) (Rice and Cogburn 1999, Lord 2001); the bean weevil (Ferron 1977); the rusty grain beetle, Cryptolestes ferrugineus (Stephens) (Lord 2001); and the red flour beetle, Tribolium castaneum (Herbst) (Rice and Cogburn 1999). Thus, if combining the two control strategies is efficacious, then there are many potential applications for control of storage insect pests.

In addition to our original hypothesis on combining use of the fungus and resistant oat cultivars for controlling sawtoothed grain beetles, we also investigated the tritrophic interactions between the seed, the herbivore, and the fungus to determine whether the level of resistance of the seed might impact the efficacy of the fungus and whether the type of seed resistance might be selected to improve the efficacy of the fungus. Throne et al. (2003) reported that duration of immature development of $O$. surinamensis could vary from 24 to $30 \mathrm{~d}$ on whole oats and number of progeny produced could vary from 1 to 40 on whole oats and from 66 to 147 on cracked oats, depending upon oat cultivar. Although we do not know the mechanisms that result in these developmental delays or in reduced numbers of progeny being produced, we hypothesized that $B$. bassiana would be more efficacious when attacking an insect that had a longer immature developmental period. Ecdysis is an important insect defense against pathogenic fungi (Fargues 1972, 1975; Vey and Fargues 1977), because the conidia that adhere to the cuticle are cast off during ecdysis. Prolongation of the stadia between molts would allow more time for completion of the hyphal penetration process, and we expected that this would result in higher rates of mortality. Thus, in the current study, we investigated the efficacy of B. bassiana for control of O. surinamensis on two whole oat cultivars on which there were differences in immature developmental time in the previous study ( $24 \mathrm{~d}$ on 'Paul' versus $30 \mathrm{~d}$ on 'Don'), on two whole oat cultivars on which there were differences in numbers of progeny produced ( 13 on 'Don' and 40 on 'Brawn'), and on two cracked oat cultivars on which there were differences in number of progeny produced (67 on 'Paul' and 147 on 'Valley'). We then conducted dose-response tests with the fungus to determine optimal application rates for control of $O$. surinamensis on cracked and whole oats.

\section{Materials and Methods}

Tritrophic Interactions. The experiment was arranged as a randomized complete block design with two rates of fungus $(0$ and $10 \mathrm{mg}$ of conidia per kilogram of oats), three whole oat cultivars and two cracked oat cultivars, and four replications of each treatment. This fungus application rate was based on levels used in a previous study with larval sawtoothed grain beetles (J.C.L., unpublished data). Lots of $20 \pm$ $0.1 \mathrm{~g}$ of whole 'Paul', whole 'Don', whole 'Brawn', cracked 'Paul', or cracked 'Valley' oats were placed in individual plastic cages $(8.26 \mathrm{~cm}$ in height by $2.86 \mathrm{~cm}$ in diameter; model 55-15 15-dram vials, Thornton Plastics, Salt Lake City, UT) with a hole cut in the lid and a 100-mesh brass screen inserted into the lid to cover the hole. The cracked oats were cracked in the 50-ml cup of a blender (model PB5A, Waring Products Corp., Winsted, CT), processed $10 \mathrm{~g}$ at a time at high speed for $3 \mathrm{~s}$. We cracked three 20 -g samples of whole 'Paul' oats by using this method to determine particle size of the resulting grain. All of the grain passed through a U.S. standard number six sieve $(3.35-\mathrm{mm}$ openings), $6.82 \pm 0.09 \mathrm{~g}$ (mean $\pm \mathrm{SD}$ ) was retained on a number eight sieve (2.38-mm openings), $10.85 \pm$ $0.10 \mathrm{~g}$ was retained on a number 20 sieve $(0.085-\mathrm{mm}$ openings), and $2.27 \pm 0.04 \mathrm{~g}$ passed through the number 20 sieve.

The cages were randomly placed in two plastic boxes ( 28 by 38.5 by $15 \mathrm{~cm}$ in height), two replications per box, on a false floor and over saturated sodium chloride solutions to maintain relative humidity at $76 \%$ (Greenspan 1977). The plastic boxes were placed in an incubator at $30 \pm 1^{\circ} \mathrm{C}$, and the oats were equilibrated to these conditions for $6 \mathrm{wk}$. 
The day before insects were added to the cages, B. bassiana conidia were added to the cages and mixed into the oats by rotating the cages. Commercially produced, unformulated conidia of $B$. bassiana isolate GHA (Emerald BioAgriculture, Butte, MT) were used. The germination rate of $>90 \%$ was assessed after $16 \mathrm{~h}$ of incubation at $26^{\circ} \mathrm{C}$ on Sabouraud dextrose agar, and there were $6.3 \times 10^{10}$ conidia per gram.

Ten 2-4-wk-old female sawtoothed grain beetles, chilled and sexed using the method of Halstead (1963), were placed in each cage. Sawtoothed grain beetles were from a laboratory colony that originated in Kansas and has been maintained in our laboratory for $>40 \mathrm{yr}$. Females were removed after $72 \mathrm{~h}$ and placed in ethanol; species and sex were confirmed (Kingsolver 1991). Adult progeny were removed from the samples every $3.5 \mathrm{~d}$, starting $14 \mathrm{~d}$ after the ovipositing females were removed, by pouring the sample into a white enamel pan and removing adults with forceps. Separate pans were used for the 0 and $10 \mathrm{ppm}$ fungal treatments to avoid contamination. Data for number of progeny produced and duration of development were analyzed using PROC GLM (SAS Institute 2001).

Dose Response on Whole and Cracked Oats. Methods were similar to those used in the tritrophic study, and only differences are noted here. There were six rates of B. bassiana $(0,5,10,25,50$, and $75 \mathrm{mg}$ of conidia per kilogram of whole oats; and $0,25,50,100,150$, and $200 \mathrm{mg}$ of conidia per kilogram of cracked oats). Only 'Paul' was used because percentage of reduction in progeny production was lowest on both cracked and whole 'Paul' oats in the tritrophic test. Thus, this would be a worst-case scenario for the dose-response study. Presumably, if we could reduce the number of progeny produced on 'Paul' with higher doses, then we should be able to do the same on other cultivars. There were 36 cages total: three replications $X$ six rates $\times$ two oat conditions (cracked or whole). Samples were checked for progeny in order of dose (lowest dose first) to minimize risk of contamination.

Dose Response on Whole Oats. An additional doseresponse study was conducted to extend the range of doses tested on whole 'Paul' oats. Methods were similar to those used in the previous study, and only differences are noted here. There were seven rates of B. bassiana $(0,25,50,75,100,150$, and $200 \mathrm{mg}$ of conidia/ $\mathrm{kg}$ of oats). There were 28 cages total: four replications $\times 7$ rates. TableCurve 2D (SYSTAT 2002) was used to fit curves to the dose-response data.

\section{Results}

Tritrophic Interactions. Variances for number of progeny produced were not homogeneous (Table 1), but increased with the means. So, the Box-Cox transformation (Box and Cox 1964) was used to homogenize variances. Data were transformed as $\frac{\left(x^{0.5}\right)-1}{0.5}$, where $x$ is number of progeny produced. After trans-
Table 1. Mean $( \pm \mathrm{SE}, n=4)$ no. of progeny produced by sawtoothed grain beetles developing on whole and cracked oats treated with the fungus $B$. bassiana

\begin{tabular}{lccrr}
\hline \hline & & \multicolumn{2}{c}{$\begin{array}{c}\text { ANOVA } \\
\text { results } \\
\text { (df }=1,6):\end{array}$} \\
$\begin{array}{c}\text { Oat condition } \\
\text { and cultivar }\end{array}$ & No fungus & Fungus & \multicolumn{2}{c}{$\begin{array}{c}\text { Fungus vs. } \\
\text { no fungus }\end{array}$} \\
\cline { 3 - 5 } & & & $F$ & $P$ \\
\hline Whole 'Paul' & $61.8 \pm 6.3$ & $38.3 \pm 5.6$ & 7.9 & 0.03 \\
Whole 'Don' & $10.5 \pm 2.0$ & $6.0 \pm 1.8$ & 2.8 & 0.15 \\
Whole 'Brawn' & $45.0 \pm 1.6$ & $14.8 \pm 2.3$ & 121 & $<0.01$ \\
Cracked 'Paul' & $117.8 \pm 3.1$ & $129.3 \pm 10.1$ & 1.2 & 0.32 \\
Cracked 'Valley' & $143.3 \pm 6.7$ & $123.0 \pm 8.3$ & 3.6 & 0.11 \\
\hline
\end{tabular}

ANOVA, analysis of variance.

formation, the interaction was significant $(F=6.9$; $\mathrm{df}=4,30 ; P<0.01$ ), so untransformed data were analyzed by oat condition/cultivar for fungal effect (variances were homogeneous within an oat condition/cultivar). Presence of the fungus reduced the number of progeny produced on whole 'Paul' and 'Brawn' oats, but not on cracked oats or on whole 'Don' oats (Table 1).

Presence of the fungus did not affect developmental time (Table 2; $F=0.18 ; \mathrm{df}=1,30 ; P=0.67$ ). Duration of development varied with cultivar and oat condition $(F=32.3 ; \mathrm{df}=4,30 ; P<0.01)$; the interaction was not significant $(F=0.37 ; \mathrm{df}=4,30 ; P=0.83)$. Variances were not homogeneous, but they could not be homogenized because there was no consistent pattern. Variances were homogeneous within an oat condition/cultivar, so we also analyzed the data by oat condition/cultivar. However, we still found no effect of the fungus on developmental time (whole 'Brawn': $F=0.13 ; \mathrm{df}=1,6 ; P=0.74$; whole 'Don': $F=0.02 ; \mathrm{df}=$ 1,$6 ; P=0.90$; whole 'Paul': $F=0.69 ; \mathrm{df}=1,6 ; P=0.40$; cracked 'Paul': $F=0.04 ; \mathrm{df}=1,6 ; P=0.85$; cracked 'Valley': $F=1.31 ; \mathrm{df}=1,6 ; P=0.30$.)

Dose Response on Whole and Cracked Oats. Number of progeny produced generally decreased with rate of $B$. bassiana on cracked (Fig. $1 ; F=17.4$; $\mathrm{df}=$ $5,10 ; P<0.01)$ and whole 'Paul' oats $(F=5.5 ; \mathrm{df}=5$, 9; $P=0.01$ ), and means ranged from 42 to 141 on cracked oats and from 26 to 88 on whole oats. Variances for whole oats were not homogeneous; however, the variances could not be homogenized because there was no consistent pattern to the variances.

Duration of development did not vary with rate of B. bassiana on cracked 'Paul' oats (Fig. $2 ; F=2.3 ; \mathrm{df}=$ $5,10 ; P=0.13)$; mean duration ranged from 22.9 to

Table 2. Mean ( $\pm \mathrm{SE}, n=4)$ duration of development (days) of sawtoothed grain beetles developing on whole and cracked oats treated with the fungus $B$. bassiana

\begin{tabular}{lcc}
\hline Oat condition and cultivar & No Fungus & Fungus \\
\hline Whole 'Brawn' & $28.8 \pm 0.46$ & $28.4 \pm 0.95$ \\
Whole 'Don' & $28.8 \pm 0.76$ & $28.9 \pm 1.23$ \\
Whole 'Paul' & $25.7 \pm 0.15$ & $26.5 \pm 0.94$ \\
Cracked 'Paul' & $24.1 \pm 0.21$ & $24.1 \pm 0.15$ \\
Cracked 'Valley' & $24.2 \pm 0.16$ & $24.5 \pm 0.07$ \\
\hline
\end{tabular}




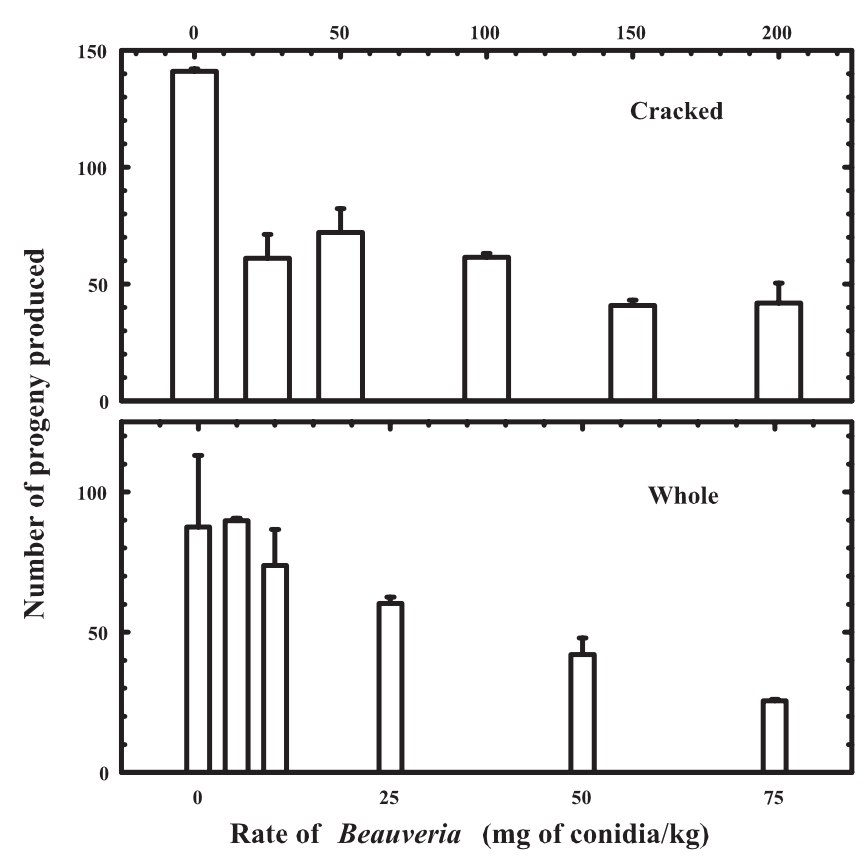

Fig. 1. Number of progeny produced (mean $\pm \mathrm{SE}, n=3$ ) by sawtoothed grain beetles developing on whole or cracked 'Paul' oats treated with varying rates of the fungus $B$. bassiana.

23.6 d. Mean duration of development did vary with rate of B. bassiana on whole 'Paul' oats (Fig. $2 ; F=9.9$; $\mathrm{df}=5,9 ; P<0.01)$; however, mean duration only ranged from 24.9 to $25.6 \mathrm{~d}$, and there was no consistent pattern to the developmental times. Thus, rate of the fungus did not affect developmental time in a predictable pattern on either cracked or whole oats.

Dose Response on Whole Oats. Number of progeny produced decreased as rate of $B$. bassiana increased (Fig. 3; $F=139$; df $=6,21 ; P<0.01$ ). A

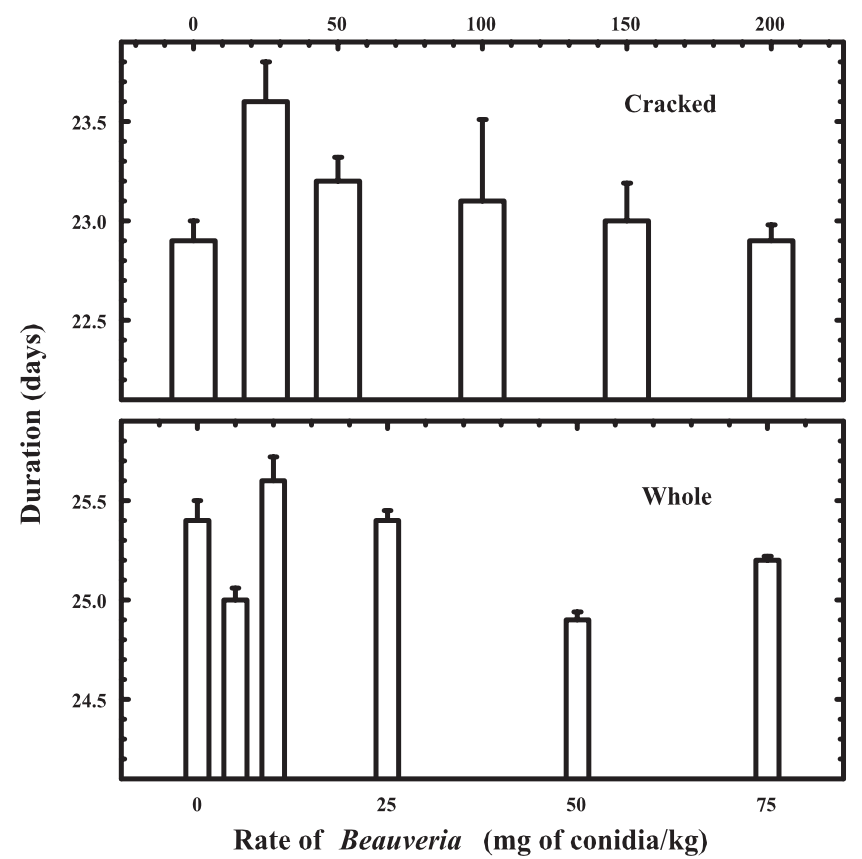

Fig. 2. Duration of immature development (mean $\pm \mathrm{SE}, n=3$ ) of sawtoothed grain beetles developing on whole or cracked 'Paul' oats treated with varying rates of the fungus B. bassiana. 

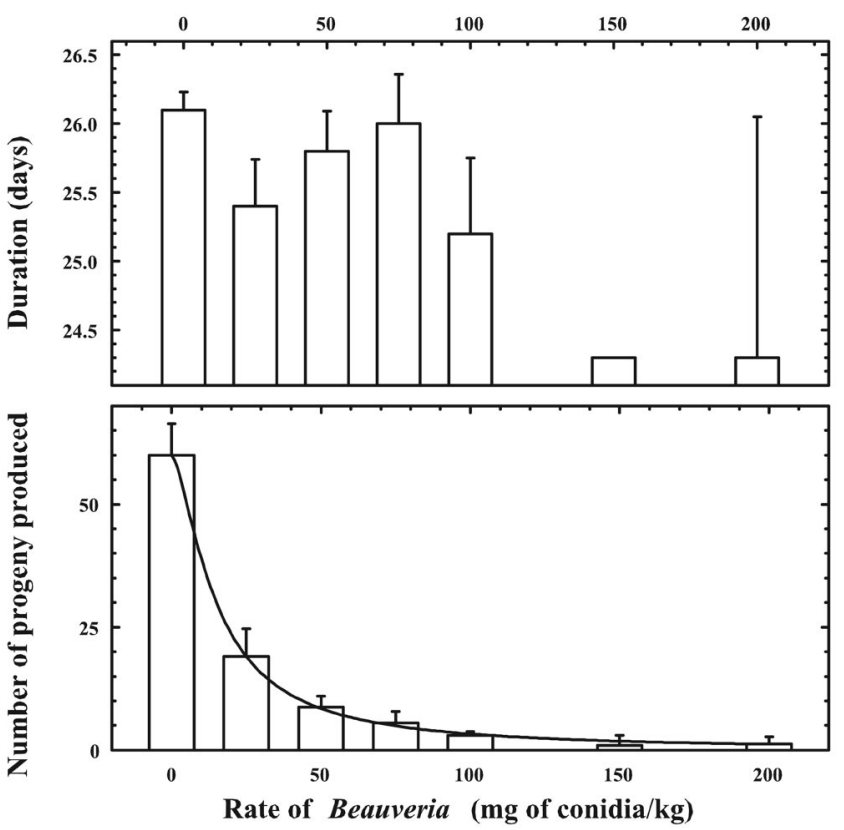

Fig. 3. Number of progeny produced and duration of development (mean $\pm \mathrm{SE}, n=4$ ) by sawtoothed grain beetles developing on whole 'Paul' oats treated with varying rates of the fungus B. bassiana. The solid line is a logistic dose-response equation fit to the data.

logistic dose-response equation was used to describe the effect of dose on number of progeny produced: $y=\frac{a}{1+\left(\frac{x}{b}\right)^{c}}$, where $y$ is number of progeny produced, $x$ is dose, $a$ is maximum number of progeny produced $=60(\mathrm{SE}=1.66), b$ is dose at which $50 \%$ of the maximum number of progeny was produced $=15$ $(\mathrm{SE}=2.10 ; 95 \% \mathrm{CL}=23.7-36.3) \mathrm{mg} / \mathrm{kg}$, and $c$ is 1.5 $(\mathrm{SE}=0.21)$.

Duration of development did not vary with rate of B. bassiana on whole 'Paul' oats (Fig. 3; $F=1.9$; $\mathrm{df}=$ $6,16 ; P=0.14)$. Variances were not homogeneous and could not be homogenized. The nonhomogeneity was due to poor survivorship and resulting high variability at high doses. There were progeny produced in only one and two replications (out of four replications) at 150 and $200 \mathrm{mg} / \mathrm{kg}$, respectively.

\section{Discussion}

Applying B. bassiana to the oats did not affect developmental time of the sawtoothed grain beetle in any of the tests. Presence of the fungus did affect number of progeny produced. In the first test, we had hypothesized that the fungus would be more effective on whole 'Don' than on whole 'Paul' oats because immature developmental time in a previous test (Throne et al. 2003) was longer on whole 'Don' than on whole 'Paul'; however, this was not the case. Percentage of reduction in number of progeny produced was $43 \%$ on whole 'Don' and $38 \%$ on whole 'Paul' treated with fungus. The percentage of reduction in progeny production was larger on whole 'Brawn' (67\%), the cultivar that had a large number of progeny produced in the previous test (40), than on whole 'Don' (43\%), the cultivar that had only 13 progeny produced in the previous test. However, we have no explanation for this difference in progeny production.

There was no effect of the fungus on insects developing in cracked oats in the test. We had chosen to apply the $B$. bassiana at $10 \mathrm{mg}$ of conidia per kilogram of oats based on results from a previous study with sawtoothed grain beetle larvae feeding on crimped wheat (J.C.L., unpublished data). However, that rate was not high enough to cause mortality when the larvae fed on cracked oats in the current study. The fungus might not be as effective on cracked oats as on whole oats because of the larger surface area of the cracked oats, possibly resulting in a lower effective dosage. In addition, the insects may move less in cracked oats, because there is a surplus of food easily available, whereas there is probably greater movement on whole oats as the insects search for food (they cannot feed on intact oats) and thus get exposed to more conidia. An alternative explanation might be that the insects are already stressed on whole oats, because cracked oats are more suitable for development (Throne et al. 2003), and thus, the stressed insects might be more susceptible to the fungus. Enhancement of $B$. bassiana-induced mortality by nutritional stress has been reported for Blissus leucopterus leucopterus (Say) (Ramoska and Todd 1985) and Chrysoperla carnea (Stephens) (Donegan and Lighthart 1989). The results from this first test led us to investigate whether increasing the rates of $B$. bassiana on 
cracked and whole oats would cause higher rates of mortality. Percentage of reductions in progeny production was $38-67 \%$ on whole oats, indicating that higher rates of $B$. bassiana might result in commercially viable reductions in progeny production.

The first dose-response test showed that adding $50 \mathrm{mg}$ of conidia per kilogram of cracked or whole 'Paul' oats resulted in a 50\% reduction in number of progeny produced. Adding 75 or $150 \mathrm{mg}$ of conidia per kilogram of whole or cracked 'Paul' oats, respectively, resulted in a $70 \%$ reduction in number of progeny produced. No further reduction was obtained by adding $200 \mathrm{mg}$ of conidia per kilogram of cracked 'Paul' oats. However, a mortality asymptote was not reached on whole 'Paul'; therefore, we conducted an additional dose-response test that showed that adding $150 \mathrm{mg}$ of conidia per kilogram of whole oats resulted in a $98 \%$ reduction in progeny produced. No further reduction was obtained by adding $200 \mathrm{mg}$ of conidia per kilogram of whole 'Paul' oats. Thus, maximum effect of the fungus on population growth would be obtained with $150 \mathrm{mg}$ of conidia per kilogram of oats.

We do not know whether the observed reductions in progeny production were due to effects of the fungus on adult or immature $O$. surinamensis, or both. Median lethal doses of B. bassiana for larvae and adults of $O$. surinamensis are nearly identical, when determined after $8 \mathrm{~d}$ (Lord 2001; J.C. L., unpublished data); however, we do not know whether the median lethal doses are the same when determined after $3 \mathrm{~d}$, which was the length of time that adults were exposed to the fungus in the current study. Few of the ovipositing females died during the 3-d oviposition period: two of 400 in the first test, four of 360 in the second test, and zero of 280 in the third test. Although there was little direct mortality to the adults, there may have been sublethal effects on numbers of eggs laid or viability of the eggs. We did expect fungus-induced mortality of immature O. surinamensis based on previous research (Searle and Doberski 1984).

The experiments described here were conducted at $30 \pm 1{ }^{\circ} \mathrm{C}$ and $76 \% \mathrm{RH}$, conditions within the range favored by $O$. surinamensis. Searle and Doberski (1984) reported that they obtained B. bassiana infections of O. surinamensis adults at $100 \% \mathrm{RH}$, but not at $\leq 90 \%$. They obtained a $91 \%$ reduction in larvae and pupae under culture conditions of $20^{\circ} \mathrm{C}$ and $100 \% \mathrm{RH}$. Fargues et al. (1997) reported that $25-28^{\circ} \mathrm{C}$ is the optimal temperature range for growth of most B. bassiana isolates tested, including GHA. Thus, the fungus' performance under putatively unfavorable temperature and relative humidity conditions is encouraging.

The combined use of resistant oat cultivars with the fungus B. bassiana shows potential for control of sawtoothed grain beetles in stored oats. A previous study (Throne et al. 2003) showed that cleaned oats should limit insect population growth to allow long-term storage of oats without insect damage. However, this study shows that if the oats are not cleaned, which is the normal storage practice, then the fungus $B$. bassiana could be used to help control sawtoothed grain beetles. A cost-benefit analysis would be required to determine the optimal rate of $B$. bassiana to use for commercial application. The study also demonstrated that two control technologies that each provides partial control of insect populations when used alone can together provide improved control, as suggested by Throne (1989). Our hypothesis that the fungus would be more efficacious on oat cultivars that prolonged larval development was not supported by our data.

\section{Acknowledgments}

We thank Sheri Anderson and Ann Redmon for excellent technical assistance, and Robert L. Meagher, Jr. (USDAARS, Gainesville, FL) and John D. Vandenberg (USDA-ARS, Ithaca, NY) for reviewing an earlier version of the manuscript.

\section{References Cited}

Adane, K., D. Moore, and S. A. Archer. 1996. Preliminary studies on the use of Beauveria bassiana to control Sitophilus zeamais (Coleoptera: Curculionidae) in the laboratory. J. Stored Prod. Res. 32: 105-113.

Arthur, F. H. 1996. Grain protectants: current status and prospects for the future. J. Stored Prod. Res. 32: 293-302.

Bourassa, C., C. Vincent, C. J. Lomer, C. Borgemeister, and Y. Mauffette. 2001. Effects of entomopathogenic Hyphomycetes against the larger grain borer, Prostephanus truncatus (Horn) (Coleoptera: Bostrichidae), and its predator, Teretriosoma nigrescens Lewis (Coleoptera: Histeridae). J. Invertebr. Pathol. 77: 75-77.

Box, G.E.P., and D. R. Cox. 1964. An analysis of transformations. J. R. Stat. Soc. Ser. B 26: 211-252.

Dal Bello, G., S. Padín, C. López Lastra, and M. Fabrizio. 2001. Laboratory evaluation of chemical-biological control of the rice weevil (Sitophilus oryzae L.) in stored grains. J. Stored Prod. Res. 37: 77-84.

Donegan, K., and B. Lighthart. 1989. Effect of several stress factors on the susceptibility of the predatory insect, Chrysoperla carnea (Neuroptera: Chrysopidae), to the fungal pathogen Beauveria bassiana. J. Invertebr. Pathol. 54: $79-84$.

Fargues, J. 1972. Étude des conditions d'infection des larves de doryphore, Leptinotarsa decemlineata Say, par Beauveria bassiana (Bals.) Vuill. (Fungi Imperfecti). Entomophaga 17: 319-337.

Fargues, J. 1975. Étude expérimentale dans la nature de l'utilisation combinée de Beauveria bassiana et d'insecticides a dose réduite contre Leptinotarsa decemlineata. Ann. Zool. Écol. Anim. 7: 247-264.

Fargues, J., M. S. Goettel, N. Smits, A. Ouedraogo, and M. Rougier. 1997. Effect of temperature on vegetative growth of Beauveria bassiana isolates from different origins. Mycologia 89: 383-392.

Ferron, P. 1977. Influence of relative humidity on the development of fungal infection caused by Beauveria bassiana (Fungi Imperfecti, Moniliales) in imagines of Acanthoscelides obtectus. Entomophaga 22: 393-396.

Fuentes-Contreras, E., J. K. Pell, and H. M. Niemeyer. 1998. Influence of plant resistance at the third trophic level: interactions between parasitoids and entomopathogenic fungi of cereal aphids. Oecologia (Berl.) 117: 426-432.

Greenspan, L. 1977. Humidity fixed points of binary saturated aqueous solutions. J. Res. Nat. Bur. Stand. 81A: $89-96$.

Halstead, D.G.H. 1963. External sex differences in storedproducts Coleoptera. Bull. Entomol. Res. 54: 119-134. 
Hidalgo, E., D. Moore, and G. Le Patourel. 1998. The effect of different formulations of Beauveria bassiana on Sitophilus zeamais in stored maize. J. Stored Prod. Res. 34: 171-179.

Ingemansen, J. A., D. L. Reeves, and R. J. Walstrom. 1986. Factors influencing stored-oat insect populations in South Dakota. J. Econ. Entomol. 79: 518-522.

Kingsolver, J. M. 1991. Adult beetles (Coleoptera), pp. 7594. In J. R. Gorham [ed.], Insect and mite pests in food: an illustrated key. U.S. Dep. Agric. Agric. Handb. 655.

Lord, J. C. 2001. Desiccant dusts synergize the effect of Beauveria bassiana (Hyphomycetes: Moniliales) on stored-grain beetles. J. Econ. Entomol. 94: 367-372.

Meikle, W. G., A. J. Cherry, N. Holst, B. Hounna, and R. H. Markham. 2001. The effects of an entomopathogenic fungus, Beauveria bassiana (Balsamo) Vuillemin (Hyphomycetes), on Prostephanus truncatus (Horn) (Col.: Bostrichidae), Sitophilus zeamais Motschulsky (Col.: Curculionidae), and grain losses in stored maize in the Benin Republic. J. Invertebr. Pathol. 77: 198-205.

Padín, S., G. Dal Bello, and M. Fabrizio. 2002. Grain loss caused by Tribolium castaneum, Sitophilus oryzae and Acanthoscelides obtectus in stored durum wheat and beans treated with Beauveria bassiana. J. Stored Prod. Res. 38: $69-74$.

Panda, N., and G. S. Khush. 1995. Host plant resistance to insects. CAB International, Wallingford, United Kingdom.

Pfannenstiel, R. S., and K. V. Yeargan. 1998. Partitioning two- and three-trophic-level effects of resistant plants on the predator, Nabis roseipennis. Entomol. Exp. Appl. 88: 203-209.

Ramoska, W. A., and T. Todd. 1985. Variation in efficacy and viability of Beauveria bassiana in the chinch bug (Hemiptera: Lygaeidae) as a result of feeding activity on selected hosts. Environ. Entomol. 14: 146-148.

Rice, W. C., and R. R. Cogburn. 1999. Activity of the entomopathogenic fungus Beauveria bassiana (Deuteromycota: Hyphomycetes) against three Coleopteran pests of stored grain. J. Econ. Entomol. 92: 691-694.
SAS Institute. 2001. The SAS system for Windows release 8.02. SAS Institute, Cary, NC

Schmale, I., F. L. Wäckers, C. Cardona, and S. Dorn. 2003. Combining parasitoids and plant resistance for the control of the bruchid Acanthoscelides obtectus in stored beans. J. Stored Prod. Res. 39: 401-411.

Searle, T., and J. Doberski. 1984. An investigation of the entomogenous fungus Beauveria bassiana (Bais.) Vuill. as a potential biological control agent for Oryzaephilus surinamensis (L.). J. Stored Prod. Res. 20: 17-24.

SYSTAT. 2002. TableCurve 2D, version 5.01. SYSTAT Software Inc., Richmond, CA.

Throne, J. E. 1989. Effects of noncatastrophic control technologies that alter life history parameters on insect population growth: a simulation study. Environ. Entomol. 18: $1050-1055$.

Throne, J. E., J. E. Baker, F. J. Messina, K. J. Kramer, and J. A. Howard. 2000. Varietal resistance, pp. 165-192. In Bh. Subramanyam and D. W. Hagstrum [eds.], Alternatives to pesticides in stored-product IPM. Kluwer Academic Publishers, Boston, MA.

Throne, J. E., D. C. Doehlert, and M. S. McMullen. 2003. Susceptibility of commercial oat cultivars to Cryptolestes pusillus and Oryzaephilus surinamensis. J. Stored Prod. Res. 39: 213-223.

Toews, M. D., T. W. Phillips, and G. W. Cuperus. 2001. Effects of wheat cultivar and temperature on suppression of Rhyzopertha dominica (Coleoptera: Bostrichidae) by the parasitoid Theocolax elegans (Hymenoptera: Pteromalidae). Biol. Control 21: 120-127.

[USDA, NASS] U.S. Department of Agriculture, National Agricultural Statistics Service. 2003. Agricultural Statistics Data Base. http://www.nass.usda.gov:81/ipedb/.

Vey, A., and Fargues, J. 1977. Histological and ultrastructural studies of Beauveria bassiana infection in Leptinotarsa decemlineata larvae during ecdysis. J. Invertebr. Pathol. 30: 207-211.

Received 30 September 2003; accepted 23 June 2004. 